\title{
APLIKASI COMMODITY SYSTEM ASSESMENT METHOD (CSAM) DALAM JALUR DISTRIBUSI BUNGA GEMITIR DARI DESA BELOK SIDAN SAMPAI PENGECER DI DENPASAR
} Application of Commodity Market Appraisal Method (CSAM) In Distribution Line of Flower Gemitir From Farmers in The Village Belok Sidan to Retailer in Denpasar

\author{
Krisna Iswara, Bambang Admadi*, Amna Hartiati \\ PS Teknologi Industri Pertanian, Fakultas Teknologi Pertanian, Universitas Udayana, Kampus Bukit \\ Jimbaran, Badung, Kode pos : 80361; Telp/Fax : (0361) 701801.
}

Diterima 20 Agustus 2018 / Disetujui 17 September 2018

\begin{abstract}
The aim of this research is to know the number of distribution channel of the flower from farmers in Petang District to the retailer, to know the impact of postharvest loss on the flower of farmers from Petang District to retailers.The research used commodity system assessment method method in the form of questionnaires distributed to farmers, collectors, and flower retailers. Impact of handling during farmer level is at clearance and sorting significance reach 15,33\%.At the level of collectors is on cleaning and sorting significantly reaches $5.17 \%$. Meanwhile, at the retailer level the impact of sorting on the loss of flower interest is significant ie $12.5 \%$. Physical damage that occurred in the form of flower broken flower at sortation. Physical damage occurs due to collisions, friction, and piles during the distribution process at the retailer level.
\end{abstract}

Keywords : CSAM, distribution channels, flower.

\section{ABSTRAK}

Penelitian Aplikasi Commodity Systerm Assesment Method (CSAM) Dalam Jalur Distribusi Bunga Gemitir Dari Petani di Desa Belok Sidan Sampai Pengecer di Denpasar bertujuan untuk mengetahui jumlah jalur distribusi bunga gemitir dari petani di Desa Belok Sidan ke pengecer, mengetahui jalur distribusi dan penanganan pascapanen bunga gemitir dari petani di Desa Belok Sidan ke pengecer, mengetahui dampak kehilangan pascapanen pada bunga gemitir dari petani di Desa Belok Sidan ke pengecer. Penelitian menggunakan metode Commodity System Assessment Method (CSAM) dengan kuisioner yang disebarkan pada petani, pengepul, dan pengecer bunga gemitir. Terdapat 2 jalur distribusi bunga gemitir dari petani di Banjar Belok sampai Denpasar, yaitu jalur I (petani-pengecer) dan jalur II (petani-pengepul-pengecer). Penanganan di tingkat petani yaitu pembersihan dan sortasi signifikansi mencapai $15,33 \%$. Pada tingkat pengepul yaitu pada pembersihan dan sortasi signifikansi mencapai $5,17 \%$. Sedangkan, pada tingkat pengecer dampak sortasi terhadap kehilangan bunga gemitir adalah signifikan yaitu $12,5 \%$. Kerusakan fisik yang terjadi berupa bunga gemitir yang rusak saat sortasi. Kerusakan fisik terjadi karena adanya benturan, gesekan, serta tumpukan-tumpukan hasil panen bunga gemitir selama proses distribusi di tingkat pengecer.

Kata kunci : : CSMA, jalur distribusi, bunga.

*Korespondensi Penulis:

Email: bambang.admadi@unud.ac.id 


\section{PENDAHULUAN}

Bali merupakan salah satu provinsi di Indonesia yang memiliki jumlah penduduk beragama Hindu sebanyak 3.247.283 penduduk. Umat Hindu melakukan persembahyangan selalu menggunakan berbagai macam bunga sebagai prasarana persembahyangan. Salah satu bunga yang digunakan adalah bunga gemitir. Bunga gemitir merupakan salah satu bunga yang sering dipakai sebagai sarana untuk persembahyangan oleh karena itu kebutuhan akan bunga gemitir semakin hari semakin banyak sehingga semakin banyak masyarakat yang menanam, bahkan tidak sedikit petani yang beralih dari menanam sayur menjadi menanam bunga gemitir (BPS, 2015).

Perkembangan areal penanaman bunga gemitir mengalami peningkatan, Hal ini dilihat dari semakin banyaknya permintaan bunga gemitir dari konsumen, di hari biasa maupun saat hari raya. Menurut Kepala desa Belok Sidan, semakin banyaknya permintaan tersebut menyebabkan semakin banyak pula petani yang memilih bunga gemitir menjadi komoditi yang ditanam di lahannya.Budidaya bunga gemitir sangat menjanjikan, selain digunakan untuk prasarana persembahyangan bunga gemitir juga dijadikan sebagai sarana untuk menyambut tamu berupa rangkaian atau kalung. Keunggulan lain dari tanaman bunga gemitir yaitu tidaklah sulit untuk merawat tanaman tersebut (Winarto, 2011).

Salah satu kawasan yang membudidayakan tanaman bunga gemitir di Bali adalah Kecamatan Petang khususnya di desa Belok Sidan. Terdapat tiga jenis bunga gemitir yang biasanya ditanam oleh petani di Bali, yaitu bunga gemitir jenis Saraswati, Srikandi dan Maharani. Dibanding dengan jenis lainnya, bunga gemitir dengan jenis Saraswati memiliki ukuran yang lebih besar dan bulat serta berwarna lebih cerah. Bunga gemitir yang dihasilkan oleh petani mengalami beberapa jalur distribusi sebelum sampai ke tangan konsumen. Jalur distribusi yang berbeda akan menyebabkan penanganan yang berbeda sehingga kerusakan pada tiap jalur distribusi juga berbeda. Dengan semakin panjangnya jalur distribusi maka semakin banyak variasi penanganan yang dialami sehingga makin besar pula tingkat kerusakannya. Melalui metode penilaian produk dalam system distribusi, diharapkan bisa mengevaluasi penanganan pascapanen bunga gemitir dari petani ke konsumen.

Penelitian sebelumnya tentang CSAM dalam distribusi komoditas adalah Budiastra, dkk (2016) yaitu tentang kubis dari petani di kecamatan Petang sampai pengecer di Denpasar yang menunjukkan bahwa di tingkat petani terdapat kehilangan pascapanen yang signifikan dibanding pengepul dan pedagang besar. Penelitian lain Surwarjana, dkk (2015) tentang CSAM dalam distribusi sawi pakcoy di kecamatan Baturiti ke pengecer menunjukkan bahwa di tingkat petani terdapat kehilangan pascapanen yang signifikan dibanding tingkat pengepul $2 \%$ dan pedagang besar $2 \%$. Penelitian tentang aplikasi CSAM pada bunga gemitir belum dilakukan, sehingga akan dilakukan penelitian tersebut.

Tujuan penelitian ini adalah untukmengetahui jumlah jalur distribusi bunga gumitir dari petani di desa Belok Sidan ke pengecer, mengetahui jalur distribusi bunga gemitir dari petani di desa Belok Sidan ke pengecer, Menentukan sistem, pelaku, dan dampak penanganan pasca panen bunga gumitir pada setiap jalur distribusi dari petani di desa Belok Sidan ke pengecer. Manfaat dari penelitian ini diharapkan dapat memberikan informasi kepada masyarakat luas tentang jenis jalur distribusi, dampak kehilangan pascapanen, penanganan pascapanen disetiap jalur distribusi pada Bunga Gemitir dari Petani ke pengecer di desa Belok Sidan sampai pengecer. 


\section{METODE PENELITIAN}

Penelitian dilaksanakan di Desa Belok Sidan, Kecamatan Petang, Kabupaten Badung. Dasar pertimbangan pengambilan lokasi penelitian ini adalah karena petani di Banjar Belok menanam bunga gemitir yang paling intensif diantara banjar-banjar yang ada di Desa Belok Sidan. Waktu penelitian di lakukan dari bulan Desember 2017 sampai Februari 2018.

Tahapan penelitian ini dimulai dari menentukan topik dan studi literatur berlanjut terhadap survey petani bunga gemitir lalu menentukan populasi dan sampel yang akan digunakan, setelah menentukan sampel dan populasi selanjutnya penyebaran kuisioner terhadap petani bunga gemitir, selajutnya data yang sudah didapatkan dari kuisioner dikumpulkan dan dianalisis menggunakan metode purposive sampling dan analisis CSAM untuk mendapatkan hasil dari penelitian.

\section{HASIL DAN PEMBAHASAN}

\section{Jalur distribusi bunga gemitir dari petani di desa Belok Sidan sampai ke pengecer.}

Jalur distribusi yang dihasilkan dalam penelitian ini terdapat 2 jalur distribusi yaitu jalur I dan II.

\section{Jalur I. Petani---Pengecer - Konsumen}

Pada jalur ini petani di Banjar Belok menjual bunga gemitir langsung ke pengecer di pasar tradisional Mambal. Petani dan pengecer pasar pada jalur ini berasal dari satu wilayah desa yang sama. Hal ini sesuai dengan penelitian Widiastuti dan Harisudin (2013) tentang saluran dan margin pemasaran jagung di kabupaten Grobongan menyatakan petani cenderung menjual hasil panennya kepada pedagang besar yang berasal dari satu wilayah yang sama.

\section{Jalur II. Petani --- Pengepul --- Pengecer - Konsumen}

Pada jalur ini petani di Banjar Belok menjual bunga gemitir kepada pengepul dengan cara mendatangi pengepul. Kemudian pengepul menjual bunga gemitir ke pengecer di pasar tradisional. Jalur ini menunjukkan bahwa pengepul sebagai memegang peranan penting untuk memastikan para pedagang besar mendapatkan pasokan bunga gemitir. Hal ini sesuasi dengan pendapat Widiastuti dan Harisudin (2013) setiap lembaga pemasaran mempunyai peranan penting dalam kegiatan pemasaran.

Penanganan pascapanen bunga gemitir pada jalur distribusi dari petani di Desa Belok Sidan ke pengecer

\section{Jalur I. Petani --- Pengecer - Konsumen}

Penanganan pascapanen pada tingkat petani adalah pemanenan, sortasi, dan pengemasan. Pemanenan bunga gemitir dilakukan saat bunga gemitir memasuki usia 90 hari dari mulai tanam bibit dari biji agar bias di panen dan belum memasuki fase generative yaitu belum muncul biji pada bunga. Sortasi dilakukan dengan cara membuang bunga yang rusak akibat terkena penyakit. Selanjutnya dilakukan pengemasan dengan menggunakan keranjang bambu.

Pada tingkat pengecer penanganan yang dilakukan adalah sortasi untuk mengetahui ada tidaknya kerusakan pada bunga gemitir. Sortasi dilakukan dengan cara membuang bunga gemitir yang rusak. Pencucian dilakukan dengan cara menyemprotkan air kepada bunga gemitir agar terlihat lebih segar sebelum dilakukan pemajangan, selanjutnya dolakukan pemajangan pad arak yang sudah tertata dengan baik tanpa menggunakan pengemasan lagi.

\section{Jalur II. Petani --- Pengepul --- Pengecer - Konsumen}

Penanganan pascapanen pada tingkat petani adalah pemanenan, sortasi, dan pengemasan. Pemanenan bunga gemitir dilakukan saat bunga gemitir memasuki usia 90 hari dari mulai tanam bibit dari biji agar bias di panen dan belum memasuki fase 
generative yaitu belum muncul biji pada bunga. Sortasi dilakukan dengan cara membuang bunga yang rusak akibat terkena penyakit, selanjutnya dilakukan pengemasan dengan menggunakan keranjang bambu.

Penanganan pascapanen pada tingkat pengepul adalah penimbangan dan pengangkutan. Penimbangan dilakukan untuk mengetahui berat bunga gemitir secara keseluruhan yang didapatkan dari hasil panen petani. Penimbangan dilakukan dengan menggunakan timbangan manual. Pada proses pengangkutan bunga gemitir yang berada dalam kemasan keranjang bambu diangkut menggunakan mobil pickup menuju pengecer.

Penanganan yang dilakukan adalah sortasi yang bertujuan untuk mengetahui ada tidaknya kerusakan pada bunga gemitir yang didapatkan dari pengepul. Sortasi dilakukan dengan cara membuang bunga gemitir yang rusak. Pada saat pemajangan bunga gemitir diletakkan dengan baik tanpa menggunakan kemasan lagi.

\section{Sistem Pascapanen bunga gemitir dari petani ke pengecer}

Tahapan sistem penanganan pascapanen bunga gemitir di setiap tingkat distribusi disajikan pada tabel 1. Berdasarkan tabel 1 terlihat bahwa penanganan pascapanen bunga geitir berbeda-beda baik tingkat petani, pengepul, dan pengecer.

\section{Sistem penanganan pascapanen di tingkat petani}

Pada penanganan ini dilakukan pemanenan, sortasi, pengemasan dan pengangkutan. Pemanenan dilakukan setelah bunga gemitir berumur 90 haridan dengan memotong bagian atas batang dari bunga gemitir dengan menggunakan gunting.Sortasi bertujuan untuk memilih atau memisahkan antara bunga gemitir yang baik dengan yang kurang baik dengan cara menghilangkan atau membuang bunga gemitir yang rusak saat panen.Setelah proses sortasi selanjutnya bunga gemitir dilaukan pengemasan. Pengemasan dilakukan dengan menggunakan keranjang bambu dengan beralaskan koran. Pengemasan bertujuan untuk mempermudah pengangkutan atau transportasi. Bunga gemitir yang sudah dikemas selanjutnya dilakukan pengangkutan menggunakan motor roda dua menuju pengepul.

\section{Sistem penanganan pascapanen di tingkat pengepul}

Penimbangan dilakukan untuk mengetahui berat bunga gemitir secara keseluruhan. Penimbangan dilakukan dengan menggunakan timbangan manual.Bunga gemitir dalam keranjang bambu yang sudah di timbang diangkut menggunakan mobil pickup menuju pengecer.

\section{Sistem penanganan pascapanen di tingkat pengecer}

Bunga gemitir dalam keranjang bambu dikeluarkan untuk dipilih dan diperiksa, apabila ada bunga yang rusak dibuang. Pencucian dilakukan agar bunga gemitir terlihat segar sebelum dilakukan pemajangan.Pemajangan dilakukan dengan menata secara rapi bunga gemitir diatas rakrak yang terbuat dari bambu tanpa menggunakan kemasan keranjang bambu.

\section{Identifikasi faktor-faktor penanganan pascapanen bunga gemitir}

Identifikasi dilakukan terhadap pelaku, kegiatan pelaku, waktu dan tempat melakukan kegiatan serta dasar dilakukannya kegiatan. Identifikasi penanganan dasar di tingkat distribusi seperti terlihat pada Tabel 2

\section{Identifikasi faktor penanganan pascapanen di tingkat petani}

Faktor-faktor yang teridentifikasi pada penanganan pascapanen di tingkat petani adalah sortasi. Sortasi bertujuan untuk memilih atau memisahkan antara bunga yang baik dengan bunga yang kurang baik dengan cara membuang bunga gemitir yang rusak terkena penyakit selain itu untuk menjaga 
mutu dan menghindari produk dari kerusakan.

\section{Identifikasi faktor penanganan pascapanen di tingkat pengepul}

Faktor-faktor yang teridentifikasi dalam penanganan pascapanen di tingkat pengepul adalah pengangkutan. Pada proses pengangkutan atau pendistribusian keranjang yang telah berisikan bunga gemitir di tempatkan pada mobil pickup untuk mendistribusikan ke pedagang besar atau pengecer.

\section{Identifikasi faktor penanganan pascapanen di tingkat pengecer}

Faktor-faktor yang teridentifikasi pada penanganan pascapanen di tingkat pengecer adalah sortasi. Sortasi dilakukan oleh pengecer dengan cara membuang bunga gemitir yang telah rusak.

Tabel 1. Diagram alir sistem pascapanen bunga gemitir dari petani di banjar Belok sampai Denpasar

\begin{tabular}{|c|c|c|c|c|c|c|c|c|c|}
\hline \multirow{2}{*}{$\begin{array}{l}\text { Tahapan sistem } \\
\text { penanganan }\end{array}$} & \multicolumn{5}{|c|}{ Symbol } & \multicolumn{4}{|c|}{ Informasi Tambahan } \\
\hline & $\mathrm{O}$ & $\mathrm{T}$ & I & $\mathrm{D}$ & $\mathrm{S}$ & Temperatur & Jarak & Waktu & Pengamatan \\
\hline $\begin{array}{l}\text { A. Tingkat Petani } \\
\text { 1. Pemanenan }\end{array}$ & & & & & & $21^{\circ}-24^{\circ}$ & $300 \mathrm{~m}$ & $\begin{array}{c}07.00- \\
09.00 \\
(120 \text { menit) }\end{array}$ & $\begin{array}{l}\text { Petani memanen bunga } \\
\text { gemitir yang sudah cukup } \\
\text { umur atau siap dipanen } \\
\text { dengan tangan (manual) }\end{array}$ \\
\hline $\begin{array}{l}\text { 2. Pembersihan dan } \\
\text { Sortasi }\end{array}$ & & & & & & $21^{\circ}-24^{\circ}$ & $50 \mathrm{~m}$ & $\begin{array}{c}09.00- \\
10.00 \\
(60 \text { menit })\end{array}$ & $\begin{array}{l}\text { Petani memisahkan bunga } \\
\text { gemitir yang rusak dan } \\
\text { membersihkan dari kotoran }\end{array}$ \\
\hline 3. Penimbangan & & & & & & $21^{\circ}-24^{\circ}$ & $50 \mathrm{~m}$ & $\begin{array}{c}10.00- \\
10.30 \\
(30 \text { menit) }\end{array}$ & $\begin{array}{l}\text { Petani menimbang bunga } \\
\text { gemitir yang sudah } \\
\text { dipanen }\end{array}$ \\
\hline 4. Pengangkutan & & & & & & $21^{\circ}-24^{\circ}$ & $50 \mathrm{~m}$ & $\begin{array}{c}10.30- \\
11.00 \\
(30 \text { menit) }\end{array}$ & $\begin{array}{l}\text { Petani memindahkan } \\
\text { bunga gemitir yang sudah } \\
\text { siap untuk dijual }\end{array}$ \\
\hline $\begin{array}{ll}\text { B. } & \text { Tingkat } \\
& \text { Pengepul } \\
\text { 1. } & \text { Penimbangan } \\
\end{array}$ & & & & & & $21^{\circ}-24^{\circ}$ & $50 \mathrm{~m}$ & $\begin{array}{c}11.00- \\
11.30 \\
(30 \text { menit) }\end{array}$ & $\begin{array}{l}\text { Menimbang bunga gemitir } \\
\text { yang akan dibeli }\end{array}$ \\
\hline $\begin{array}{l}\text { 2. Pembersihan dan } \\
\text { sortasi }\end{array}$ & & & & & & $21^{\circ}-24^{\circ}$ & $50 \mathrm{~m}$ & $\begin{array}{c}11.30- \\
11.45 \\
(15 \text { menit) }\end{array}$ & $\begin{array}{l}\text { Memisahkan bunga gemitir } \\
\text { yang baik dan rusak, } \\
\text { membersihkan dari kotoran }\end{array}$ \\
\hline 3. Pengangkutan & & & & & & $21^{\circ}-24^{\circ}$ & $42 \mathrm{~km}$ & $\begin{array}{c}11.45- \\
13.05 \\
\text { (80 menit) }\end{array}$ & $\begin{array}{l}\text { Mengangkut bunga gemitir } \\
\text { dari pengepul sampai } \\
\text { kepengecer }\end{array}$ \\
\hline $\begin{array}{ll}\text { C. } & \text { Tingkat } \\
& \text { Pengecer } \\
\text { 1. } & \text { Penimbangan } \\
\end{array}$ & & & & & & $26^{\circ}-28^{\circ}$ & $50 \mathrm{~m}$ & $\begin{array}{c}13.05- \\
13.25 \\
\text { (20 menit) }\end{array}$ & $\begin{array}{l}\text { Menimbang bunga gemitir } \\
\text { yang akan dibeli }\end{array}$ \\
\hline $\begin{array}{l}\text { 2. Pembersihan dan } \\
\text { sortasi }\end{array}$ & & & & & & $26^{\circ}-28^{\circ}$ & $50 \mathrm{~m}$ & $\begin{array}{c}13.25- \\
13.35 \\
(10 \text { menit) }\end{array}$ & $\begin{array}{l}\text { Memisahkan bunga gemitir } \\
\text { yang baik dan rusak, } \\
\text { membersihkan dari kotoran }\end{array}$ \\
\hline 3. Pemajangan & & & & & & $26^{\circ}-28^{\circ}$ & $50 \mathrm{~m}$ & $\begin{array}{c}13.35- \\
13.40 \\
(5 \text { menit })\end{array}$ & $\begin{array}{l}\text { Bunga gemitir dipajang } \\
\text { untuk dijual ditempat } \\
\text { pedagang pengecer }\end{array}$ \\
\hline
\end{tabular}


Tabel 2. Identifikasi faktor penanganan pascapanen bunga gemitir.

\begin{tabular}{|c|c|c|c|c|c|c|}
\hline $\begin{array}{l}\text { Tahapan } \\
\text { Penanganan }\end{array}$ & $\begin{array}{l}\text { Siapa } \\
\text { Pelakunya? }\end{array}$ & $\begin{array}{l}\text { Apa yang } \\
\text { dilakukan }\end{array}$ & $\begin{array}{l}\text { Bagaimana } \\
\text { Melakukannya } \\
\end{array}$ & $\begin{array}{l}\begin{array}{l}\text { Kapan } \\
\text { dilakukan }\end{array} \\
\end{array}$ & $\begin{array}{l}\text { Mengapa } \\
\text { Dilakukan }\end{array}$ & $\begin{array}{l}\text { Dimana } \\
\text { Dilakukan } \\
\end{array}$ \\
\hline $\begin{array}{l}\text { A. Tingkat Petani } \\
\text { 1. Pemanenan }\end{array}$ & Petani & $\begin{array}{l}\text { Memetik bunga } \\
\text { gemitir yang sudah } \\
\text { culkup umur atau } \\
\text { siap dipanen }\end{array}$ & $\begin{array}{l}\text { Bunga gemitir } \\
\text { dipotong } \\
\text { menggunakan } \\
\text { gunting }\end{array}$ & $\begin{array}{l}\text { Saat panen di } \\
\text { pagi hingga } \\
\text { siang hari }\end{array}$ & $\begin{array}{l}\text { Untuk memetik } \\
\text { bunga gemitir } \\
\text { yang telah siap } \\
\text { panen }\end{array}$ & Di kebun \\
\hline $\begin{array}{l}\text { 2. Pembersihan } \\
\text { dan Sortasi }\end{array}$ & Petani & $\begin{array}{l}\text { Memisahkan bunga } \\
\text { gemitir yang rusak } \\
\text { dan membersihkan } \\
\text { dari koto'ran }\end{array}$ & $\begin{array}{l}\text { Bunga gemitir } \\
\text { dibersihkan dari } \\
\text { kotoran }\end{array}$ & $\begin{array}{l}\text { Setelah bunga } \\
\text { gemitir kering }\end{array}$ & $\begin{array}{l}\text { Untuk } \\
\text { memisahkan } \\
\text { bunga gemitir } \\
\text { yang baik dengan } \\
\text { bunga gemitir } \\
\text { yang rusak }\end{array}$ & $\begin{array}{l}\text { Di rumah petani } \\
\text { atau dikebun }\end{array}$ \\
\hline 3. Penimbangan & Petani & $\begin{array}{l}\text { Menimbang bunga } \\
\text { gemitir yang sudah } \\
\text { dipanen }\end{array}$ & $\begin{array}{l}\text { Bunga gemitir } \\
\text { ditimbang } \\
\text { menggunakan } \\
\text { timbangan manual }\end{array}$ & $\begin{array}{l}\text { Setelah bunga } \\
\text { gemitir } \\
\text { dibersihkan } \\
\text { dan disortasi }\end{array}$ & $\begin{array}{l}\text { Untuk } \\
\text { mengetahui berat } \\
\text { bunga gemitir } \\
\text { setelah di } \\
\text { bersihkan dan } \\
\text { disortasi }\end{array}$ & $\begin{array}{l}\text { Di kebun atau di } \\
\text { Di rumah petani }\end{array}$ \\
\hline 4. Pengangkutan & Petani & $\begin{array}{l}\text { Memindahkan } \\
\text { bunga gemitir yang } \\
\text { sudah siap untuk } \\
\text { dijual }\end{array}$ & $\begin{array}{l}\text { Bunga gemitir yang } \\
\text { sudah dimasukan } \\
\text { kedalam kranjang } \\
\text { bambu kemudian } \\
\text { dibawa } \\
\text { menggunakan } \\
\text { mobil bak terbuka } \\
\text { dan ditutupi terpal }\end{array}$ & $\begin{array}{l}\text { Setelah bunga } \\
\text { gemitir di } \\
\text { masukakn } \\
\text { kedalam } \\
\text { kranjang } \\
\text { bambu dan } \\
\text { siap dijual ke } \\
\text { pengepul } \\
\end{array}$ & $\begin{array}{l}\text { Untuk } \\
\text { memindahkan } \\
\text { bunga gemitir } \\
\text { dan siap untuk } \\
\text { dijual ke } \\
\text { pengepul }\end{array}$ & Di rumah petani \\
\hline $\begin{array}{ll}\text { B. } & \text { Tingkat } \\
\text { Pengepul } \\
\text { 1. Penimbangan }\end{array}$ & Pengepul & $\begin{array}{l}\text { Menimbang bunga } \\
\text { gemitir yang akan } \\
\text { dibeli }\end{array}$ & $\begin{array}{l}\text { Menimbang bunga } \\
\text { gemitir dengan } \\
\text { timbangan manual }\end{array}$ & $\begin{array}{l}\text { Setelah bunga } \\
\text { gemitir siap } \\
\text { dijual oleh } \\
\text { petani }\end{array}$ & $\begin{array}{l}\text { Untuk } \\
\text { mengetahui berat } \\
\text { bunga gemitir } \\
\text { yang akan dibeli }\end{array}$ & $\begin{array}{l}\text { Di rumah } \\
\text { pengepul }\end{array}$ \\
\hline $\begin{array}{l}\text { 2. Pembersihan } \\
\text { dan sortasi }\end{array}$ & Pengepul & $\begin{array}{l}\text { Memisahkan bunga } \\
\text { gemitir yang baik } \\
\text { dan rusak, } \\
\text { membersihkan dari } \\
\text { kotoran }\end{array}$ & $\begin{array}{l}\text { Bunga gemitir } \\
\text { dibersihkan dari } \\
\text { kotoran tanah }\end{array}$ & $\begin{array}{l}\text { Setelah bunga } \\
\text { gemitir } \\
\text { dikirim oleh } \\
\text { pengepul dan } \\
\text { tiba di } \\
\text { pedagang }\end{array}$ & $\begin{array}{l}\text { Untuk } \\
\text { memisahkan } \\
\text { bunga gemitir } \\
\text { yang baik dan } \\
\text { yang rusak }\end{array}$ & $\begin{array}{l}\text { Dirumah } \\
\text { pedagang }\end{array}$ \\
\hline 3. Pengangkutan & Pengepul & $\begin{array}{l}\text { Mengangkut bunga } \\
\text { gemitir dari } \\
\text { pengepul sampai } \\
\text { kepedagang }\end{array}$ & $\begin{array}{l}\text { Bunga gemitir yang } \\
\text { sudah dimasukan } \\
\text { kedalam kranjang } \\
\text { bambu kemudian } \\
\text { diikat dan dibawa } \\
\text { menggunakan } \\
\text { mobil bak terbuka } \\
\text { dan ditutupi terpal }\end{array}$ & $\begin{array}{l}\text { Setelah bunga } \\
\text { gemitir di } \\
\text { masukakn } \\
\text { kedalam } \\
\text { kranjang } \\
\text { bambu dan } \\
\text { siap dijual ke } \\
\text { pedagang }\end{array}$ & $\begin{array}{l}\text { Untuk } \\
\text { memindahkan } \\
\text { bunga gemitir } \\
\text { dan siap untuk } \\
\text { dijual ke pedaang }\end{array}$ & $\begin{array}{l}\text { Di rumah } \\
\text { pengepul }\end{array}$ \\
\hline $\begin{array}{ll}\text { C. } & \text { Tingkat } \\
\text { Pedagang } \\
\text { 1. }\end{array}$ & Pedagang & $\begin{array}{l}\text { Menimbang bunga } \\
\text { gemitir yang akan } \\
\text { dibeli }\end{array}$ & $\begin{array}{l}\text { Menimbang bunga } \\
\text { gemitir dengan } \\
\text { timbangan manual }\end{array}$ & $\begin{array}{l}\text { Setelah bunga } \\
\text { gemitir siap } \\
\text { dijual oleh } \\
\text { pengepul }\end{array}$ & $\begin{array}{l}\text { Untuk } \\
\text { mengetahui berat } \\
\text { bunga gemitir } \\
\text { yang akan dibeli }\end{array}$ & $\begin{array}{l}\text { Dirumah } \\
\text { pedagang }\end{array}$ \\
\hline $\begin{array}{l}\text { 2. Pembersihan } \\
\text { dan sortasi }\end{array}$ & Pedagang & $\begin{array}{l}\text { Memisahkan bunga } \\
\text { gemitir yang baik } \\
\text { dan rusak, } \\
\text { membersihkan dari } \\
\text { kotoran }\end{array}$ & $\begin{array}{l}\text { Bunga gemitir } \\
\text { dibersihkan dari } \\
\text { kotoran tanah }\end{array}$ & $\begin{array}{l}\text { Setelah bunga } \\
\text { gemitir } \\
\text { dikirim oleh } \\
\text { pengepul dan } \\
\text { tiba di } \\
\text { pedagang }\end{array}$ & $\begin{array}{l}\text { Untuk } \\
\text { memisahkan } \\
\text { bunga gemitir } \\
\text { yang baik dan } \\
\text { yang rusak }\end{array}$ & $\begin{array}{l}\text { Dirumah } \\
\text { pedagang }\end{array}$ \\
\hline 3. Pengangkutan & Pedagang & $\begin{array}{l}\text { Mengangkut bunga } \\
\text { gemitir dari } \\
\text { pedagang sampai } \\
\text { ke pengecer }\end{array}$ & $\begin{array}{l}\text { Bunga gemitir yang } \\
\text { sudah dimasukan } \\
\text { kedalam kranjang } \\
\text { bambu kemudian } \\
\text { diikat dan dibawa } \\
\text { menggunakan } \\
\text { mobil bak terbuka } \\
\text { dan ditutupi terpal }\end{array}$ & $\begin{array}{l}\text { Segera setelah } \\
\text { bunga gemitir } \\
\text { di } \\
\text { sortasi/dibersi } \\
\text { hkan }\end{array}$ & $\begin{array}{l}\text { Untuk } \\
\text { memindahkan } \\
\text { bunga gemitir } \\
\text { dan siap untuk } \\
\text { dijual ke } \\
\text { pengecer }\end{array}$ & $\begin{array}{l}\text { Di rumah } \\
\text { pedagang }\end{array}$ \\
\hline
\end{tabular}




\begin{tabular}{|c|l|l|l|l|l|l|}
\hline $\begin{array}{c}\text { D. Pengecer } \\
\text { 1. Penimbangan }\end{array}$ & Pengecer & $\begin{array}{l}\text { Menimbang bunga } \\
\text { gemitir yang akan } \\
\text { dibeli }\end{array}$ & $\begin{array}{l}\text { Menimbang bunga } \\
\text { gemitir dengan } \\
\text { timbangan manual }\end{array}$ & $\begin{array}{l}\text { Setelah bunga } \\
\text { gemitir siap } \\
\text { dijual oleh } \\
\text { pengepul }\end{array}$ & $\begin{array}{l}\text { Untuk } \\
\text { mengetahui berat } \\
\text { bunga gemitir } \\
\text { yang akan dibeli }\end{array}$ & $\begin{array}{l}\text { Di pasar tempat } \\
\text { pedagang }\end{array}$ \\
\hline $\begin{array}{l}\text { 2. Pembersihan } \\
\text { dan sortasi }\end{array}$ & Pengecer & $\begin{array}{l}\text { Membersihkan } \\
\text { bunga dari kotoran } \\
\text { dan memisahkan } \\
\text { bunga gemitir yang } \\
\text { baik dan jelek }\end{array}$ & $\begin{array}{l}\text { Bunga gemitir } \\
\text { dibersihkan dari } \\
\text { kotoran tanah }\end{array}$ & $\begin{array}{l}\text { Setelah bunga } \\
\text { gemitir } \\
\text { diturunkan } \\
\text { dari mobil bak } \\
\text { terbuka }\end{array}$ & $\begin{array}{l}\text { Untuk } \\
\text { membersihkan } \\
\text { bunga gemitir } \\
\text { dari kotoran serta } \\
\text { memisahkan } \\
\text { bunga gemitir } \\
\text { yang rusak dan } \\
\text { vang jelek }\end{array}$ & Di pasar \\
\hline 3. Pemajangan & Pengecer & $\begin{array}{l}\text { Memajang bunga } \\
\text { gemitir }\end{array}$ & $\begin{array}{l}\text { Bunga gemitir } \\
\text { dipajang untuk } \\
\text { dijual di tempat } \\
\text { pedagang pengecer }\end{array}$ & $\begin{array}{l}\text { Setelah bunga } \\
\text { gemitir selesai } \\
\text { dilakukan } \\
\text { pembersihan } \\
\text { dang sortasi }\end{array}$ & $\begin{array}{l}\text { Untuk memajang } \\
\text { bunga gemitir } \\
\text { sehingga } \\
\text { konsumen bisa } \\
\text { membelinya }\end{array}$ & Di pasar \\
\hline
\end{tabular}

Dampak penanganan selama distribusi terhadap kehilangan pascapanen bunga gemitir dari petani di Banjar Belok ke pengecer.

1. Hasil Panen, Kehilangan saat Sortasi, Hasil Penjualan, Presentase Penjualan dan Presentase Kehilangan di Tingkat Petani.

Hasil panen, kehilangan saat sortasi, dan hasil panen bersih di tingkat petani dapat dilihat pada Tabel 3. Pada Tabel 3 menunjukkan bahwa nilai rata- rata panen dengan persentase kehilangan pada saat sortasi terbesar berada pada petani di jalur 2 dengan jumlah $52 \mathrm{~kg}(14,05 \%)$ dan persentase penjualan bersih bunga gemitir sebesar 318 $\operatorname{kg}(84,67 \%)$. Bunga gemitir yang mengalami sortasi yaitu bunga gemitir yang telah rusak dan tidak layak dijual.

Tabel 3. hasil panen, kehilangan saat sortasi, hasil panen bersih di tingkat petani.

\begin{tabular}{cccc}
\hline Petani & Panen $(\mathrm{Kg})$ & $\begin{array}{c}\text { Kehilangan saat sortasi } \\
(\mathrm{Kg})\end{array}$ & Hasil penjualan (kg) \\
\hline Rata-rata & 300 & 46 & 254 \\
\hline Persentase (\%) & & 15,33 & 84,67 \\
\hline
\end{tabular}

2. Hasil pembelian, kehilangan saat sortasi, dan penjualan di tingkat pengepul.

Tabel 4. Hasil pembelian, kehilangan saat sortasi dan penjualan di tingkat pengepul.

\begin{tabular}{cccc}
\hline Pengepul & Pembelian $(\mathrm{Kg})$ & $\begin{array}{c}\text { Kehilangan saat } \\
\text { sortasi }\end{array}$ & Hasil penjualan \\
\hline Rata-rata & 41,43 & 2,14 & 39,29 \\
\hline Persentase (\%) & & 5,17 & 94,83 \\
\hline
\end{tabular}

Pada Tabel 4 menunjukkan nilai rata-rata pembelian bunga gemitir. persentase penjualan dan kehilangan saat sortasi memiliki hasil pada tiap pengepul berbeda. Rata-rata persentase kehilangan sortasi pada tingkat pengepul yaitu $5,17 \%$ dan hasil penjualan 94,83\%. Bunga gemitir yang mengalami sortasi yaitu bunga gemitir yang telah rusak dan tidak layak dijual.
3. Hasil Pembelian, Kehilangan saat Sortasi, dan Penjualan di Tingkat Pengecer.

Pada tabel 5 menunjukkan hasil panen, kehilangan saat sortasi, dan hasil panen bersih dengan presentase hasil panen bersih bunga gemitir mencapai $87,5 \%$ dan kehilangan saat sortasi $12,5 \%$. Kehilangan saat sortasi bunga gemitir terjadi karena mengalami kerusakan saat pemanenan. 
Tabel 5. Hasil panen, kehilanga saat sortasi, dan hasil panen bersih di tingkat petani.

\begin{tabular}{cccc}
\hline Petani & Hasil panen $(\mathrm{kg})$ & Kehilangan saat sortasi $(\mathrm{kg})$ & Hasil panen bersih $(\mathrm{kg})$ \\
\hline Rata-rata & 48 & 6 & 42 \\
\hline Presentase $\%$ & & 12,5 & 87,5 \\
\hline
\end{tabular}

$\begin{array}{ll}\text { Dampak Penanganan Terhadap } & \begin{array}{l}\text { dirtribusinya. Dampak penanganan } \\ \text { pascapanen bunga gemitir berdasarkan }\end{array} \\ \text { Pascapanen Bunga gemitir } & \text { tingkat kehilangan pascapanen yang tidak } \\ \text { Dampak Penanganan pascapanen bunga } & \text { signifikan, signifikan dan sangat signifikan } \\ \text { gemitir dalam distribusinya, menunjukkan } & \text { dapat dilihat pada Tabel } 6 .\end{array}$

Tabel 6. Persentase dampak penanganan terhadap kehilangan pascapanen

\begin{tabular}{llll}
\hline & Tidak signifikan & Signifikan & Sangat signifikan \\
\hline $\begin{array}{l}\text { A. Tingkat Petani } \\
\text { 1. Panen }\end{array}$ & $\sqrt{ }$ & \\
2. Pembersihan dan sortasi & & $\sqrt{ }(15,33 \%)$ & \\
3. Penimbangan & $\sqrt{ }$ & \\
4. Pengangkutan & $\sqrt{ }$ & \\
\hline B.Tingkat Pengepul & & $\sqrt{ }(5,12 \%)$ \\
\hline 1. Penimbangan & $\sqrt{ }$ & \\
2. Pembersihan dan sortasi & & \\
3. Pengangkutan & $\sqrt{ }$ & \\
\hline C. Pengecer & & $\sqrt{ }(12,5 \%)$ \\
\hline 1. Penimbangan & $\sqrt{ }$ & \\
2. Pembersihan dan sortasi & & $\sqrt{ }$ & \\
3. Pemajangan & &
\end{tabular}

$\begin{array}{ll}\text { Keterangan: Tidak signifikan } & :<5 \% \\ \text { Signifikan } & : 5-30 \% \\ \text { Sangat Signifikan } & :>30 \% \text { (La Gra, 1999) } \\ \text { V } & : \text { Posisi signifikansi }\end{array}$

\section{Dampak penanganan di tingkat Petani}

Dampak sortasi terhadap kehilangan signifikansi mencapai $15,33 \%$. Hal ini disebabkan oleh banyaknya bunga gemitir yang terbuang pada saat penen karena rusak dan tidak layak dijual.

\section{Dampak penanganan di tingkat Pengepul}

Dampak sortasi terhadap kehilangan bunga gemitir adalah 5,17\%. Hal ini disebabkan jarak tempuh penerimaan bunga gemitir dari petani ke pengepul yang dilalui tidak jauh sehingga kerusakan akibat dampak proses distribusi hanya sedikit. Sortasi dilakukan dengan menghilangkan bunga yang rusak.

\section{Dampak penanganan di tingkat Pengecer}

Bunga gemitir yang dijual dipengecer dilakukan dengan cara dipajang serta ditata diatas box kayu tanpa menggunakan kemasan. Dampak sortasi terhadap kehilangan bunga gemitir adalah signifikan yaitu $12,5 \%$. Kerusakan fisik terjadi karena adanya benturan, gesekan, serta tumpukantumpukan selama proses distribusi di tingkat pengecer. Bunga yang mengalami kerusakan fisik, selain tampilannya menjadi kurang baik juga akan memicu terjadinya pembusukan (Qanitah, 2011).

\section{KESIMPULAN}

\section{Kesimpulan}

Berdasarkan penelitian yang telah dilakukan maka dapat disimpulkan beberapa hal sebagai berikut:

Terdapat 2 jalur distribusi bunga gemitir 
dari petani di Banjar Belok sampai Denpasar, yaitu jalur I (petani-pengecer), jalur II (petani-pengepul-pengecer).

Faktor-faktor yang teridentifikasi dalam penanganan pascapanen bunga gemitir yaitu (a) faktor penanganan di tingkat petani adalah pembersihan dan sortasi, (b) faktor penanganan di tingkat pengepul adalah pengangkutan, dan (c) faktor penanganan di tingkat pengecer adalah pembersihan, sortasi dan pemajangan.

Dampak penanganan selama tingkat petani yaitu pada pembersihan dan sortasi signifikansi mencapai $15,33 \%$. Pada tingkat pengepul yaitu pada pembersihan dan sortasi signifikanmencapai $5,17 \%$. Sedangkan, pada tingkat pengecer dampak sortasi terhadap kehilangan bunga gemitir adalah signifikan yaitu $12,5 \%$. Kerusakan fisik yang terjadi berupa bunga gemitir yang rusak saat sortasi. kerusakan fisik terjadi karena adanya benturan, gesekan, serta tumpukan-tumpukan selama proses distribusi di tingkat pengecer.

\section{Saran}

Berdasarkan hasil penelitian ini dapat disarankan perlu dilakukan perbaikanperbaikan penanganan pascapanen pada tiap tingkat terutama pada penanganan pascapanen dan perbaikan penyimpanan, transportasi, distribusi, dan pemasaran bunga gemitir agar menghasilkan produk hortikultura yang baik.Serta memberikan penjelasan dan arahan pada pelaku penanganan pasca panen sesuai dengan cara- cara penanganan yang baik.

\section{DAFTAR PUSTAKA}

Budiastra, I Gede., Triani, I G. A. L., dan Amna Hartiati., 2016. " Aplikasi Commodity system Assesment Method (Csam) Dalam Distribusi Kubis (Brassica Oleracea Var Capitata) Dari Petani Di Kecamatan Petang Ke Pengecer". Jurnal Rekayasa Proses dan Manajemen Agroindustri. Vol.5 No1. Hal 13-19.

La Graa, 1999. A Commodity System Assessment Methodology for Problem and project Identification. Postharvest Institute for Parishable, College of Agriculture. University of Idaho, Moscow.

Suwarjana, E. P., Triani, I G. A. L., dan Harsujuwono, B., A., 2015. “ Aplikasi Commodity syatem Assesment Method (Csam) Dalam Distribusi Sawi Pakcoy (Brassica Rapa L) Dari Petani Di Kecamatan Baturiti Ke Pengecer”. Jurnal Rekayasa Proses dan Manajemen Agroindustri. Vol.3 No4. Hal 140-148.

Widiastuti, N dan M, Harisudin. 2013. Saluran dan margin pemasaran jagung di Kabupaten Grobogan.

Winarto, L. 2011. Tagetes Erecta Berguna Bagi Kita. Artikel. Badan Penelitian dan Pengembangan Sumatera Utara. Diakses pada tanggal 17 Oktober 2014. 